\title{
Innovative Unconventional Formation Evaluation Approach in a Tight Oil Reservoir, Xinjiang Oilfield, China
}

\author{
Guobin Wang \\ Exploration Department of Xinjiang Oilfield Resources \\ CNPC \\ Karamay, China \\ wgb1976@petrochina.com.cn
}

\author{
Jinlong Wu \\ Petro Technical Service \\ Schlumberger \\ Beijing, China \\ JWu7@slb.com
}

\author{
Fangfang $\mathrm{Wu}$ \\ Petro Technical Service \\ Schlumberger \\ Beijing, China \\ FWu2@slb.com \\ Lei Yang \\ Petro Technical Service \\ Schlumberger \\ Beijing, China \\ LYang6@slb.com
}

\begin{abstract}
Complicated minerals, high total organic carbon (TOC) content, and thin interbeded layers aggravated the complexity of logging responses and made it very difficult to find the target zone of the tight oil reservoir in the Jimusaer depression in northwestern China. Horizontal well drilling is extremely difficult in the formation due tohigh heterogeneity and uncertain fault, it caused hundreds of millions of dollars' loss to drill one horizontal well without targeting the zone. To maximize oil production with low cost, an integrated solution is provided. First, we used an unconventional evaluation approach to integrate an elemental capture spectroscopy log with other logs to get accurate reservoir characteristics. Second, we built a 3D structural model to target the best reservoir. Third, we combined Reservoir Quality (RQ), Completion Quality (CQ), and 3D structural models to optimize the stimulation design and enhance production. With this approach, which integrates the $R Q$ and $C Q$ parameters into the $3 D$ structural model, not only can we evaluate the effective porosity, saturation, minerals, fractures, TOC, and stress profile along the wellbore, but also can get a clear picture of these properties in 3D distribution so that multistage hydraulic fracturing design can be made more effectively and at lower cost. Application of this approach on several wells proved that it is an effective way for tight oil reservoir evaluation and production enhancement.
\end{abstract}

Keywords-Tight oil;Unconventional evaluation;Horizontal well;3D structural modeling;Stimulation design

\section{INTRODUCTION}

With the rapid development of the world economy, the exploration and development of unconventional oil and gas resources have become a new hot frontier in China. As an important subset of unconventional reservoirs, lowpermeability tight oil reservoirs have aroused general interest. The study area is located in Junggar basin in northwestern China. The target formation is the Lucaogou formation of Permain age. Based on regional study, two high-quality pay zones are identified, named "Upper sweet spot" and "Lower sweet spot." But both of the sweet spots are characterized by complex lithology and low permeability $[1,2]$.

Natural fractures are very important for tight oil reservoirs to improve permeability. However, only a few fractures are identified in the pilot well sweet spot zone from images. To increase the oil production, the operator had to drill horizontal wells and conduct multistage stimulation with the objective of increasing reservoir contact to improve the production [3]. However, although they had attempted both of these, few wells got good production performance.

Complex lithology and high heterogeneity, including quartz, albite, potassium feldspar, calcite, dolomite, and kerogen content, aggravated the complexity of logging responses and made it very difficult to target and evaluate the zone of interest. Besides that, there is a common misunderstanding that regardless of where the borehole is positioned within the structure, as long as the borehole is located within or close to the target reservoir, hydraulic stimulation can connect the well to the reservoir and the well will produce efficiently. Heterogeneity of properties along horizontal wells has a significant impact on the quality of completion as well as on production from each stage [4]. This heterogeneity can be seen in the quality of the reservoir, such as changes in kerogen content and maturity, free porosity, and water saturation, and in factors that directly affect the course of induced fracturing in the well. These factors can be faults, natural fractures, stressregime changes, etc[5].

Our study provided an innovative approach for tight oil reservoir development, from reservoir evaluation for the pilot well to optimization of horizontal well drilling and stimulation. First, in the pilot well, we integrated an elemental capture spectroscopy log with a high-resolution 
resistivity image log, magnetic resonance log, dipole sonic data, and conventional logs to get accurate lithology, TOC, porosity, oil saturation and stress profile with an unconventional evaluation approach. Second, we conducted an accurate well correlation and built a 3D structural model with new technology based on resistivity image data and conventional logs to target the best reservoir as much as possible when drilling the horizontal well. Third, we combined Reservoir Quality (RQ), Completion Quality (CQ), and 3D structural models to optimize the stimulation design and enhance the oil production.

\section{CONVENTIONAL UNCONVENTIONAL EVALUATION FOR PILOT WELL}

For unconventional evaluation, the parameters can be classified into two unique classes, RQ and CQ. Variables included in the class of reservoir quality usually have to do with the intrinsic quality of the rock, such as preserved and converted organic components, free porosity distribution, pore space structure, hydrocarbon versus water saturation in the pore spaces, adsorbed volume components of gas, and lithological makeup.

Properties grouped under completion quality (Fig .1) are those which will have an effect on production even if the reservoir quality remains the same. Natural fractures, faults, changes in stress state of the rock, completion design and type, and even quality of cement can be included in this category.

Because of the heterogeneity of the reservoir, an advanced acquisition program is highly recommended. From X-ray diffraction and local experience, minerals and their volumes can be solved in ELAN using ECS and HNGS data. And then we can calculate TOC content through different direct methods. In unconventional reservoirs, combinable magnetic resonance can be a perfect indicator for porosity and pore structure, and formation microimaging (FMI) combined with SonicScanner data can be used for fracture identification and evaluation. SonicScanner data can be used for geomechanical analysis, which has been covered by many papers. After all these steps, RQ can be evaluated by combing kerogen, effective porosity, saturation, mineral content, and fractures. And CQ can be evaluated from geomechincal analysis

However, for horizontal wells, beside the conventional RQ and CQ evaluation, how these parameters are distributed in the 3D area also becomes very important, which is why we bring the $3 \mathrm{D}$ structure modeling into the unconventional evaluation.

\section{3D STRUCTURE MODELING}

For horizontal well correlation and structure analysis, we developed a new workflow using Schlumberger's Petrel and eXpand ${ }^{\mathrm{BG}}$ structural modeling software with image and conventional logs (Fig .2).

First, dips were picked from FMI images. FMI images play a very important part in horizontal well correlation and structure analysis; they can not only indicate the presence of a formation, but can also show the relationship between the well trajectory and the formation. If the bedding emoticon shows a sad face, we know the well is drilling down the formation; if the bedding shows a smiling face, then we know the well is drilling up the formation, so we can correlate the logs up and down and can get a more accurate correlation.

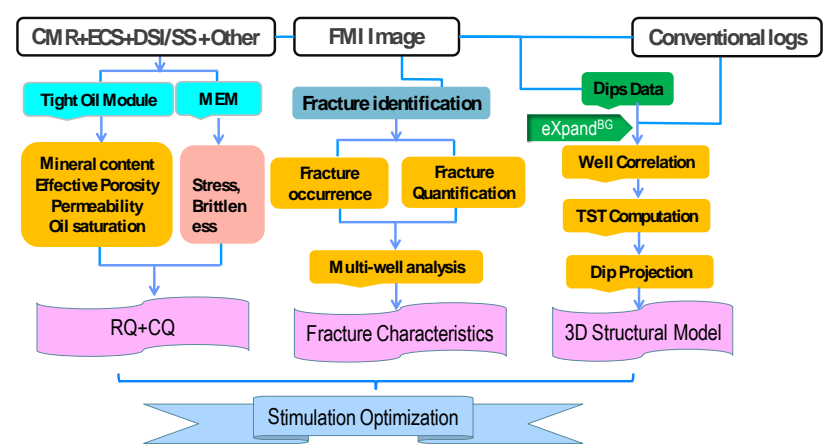

Figure 1. Unconventional Evaluation Workflow for Tight Oil Reservoir
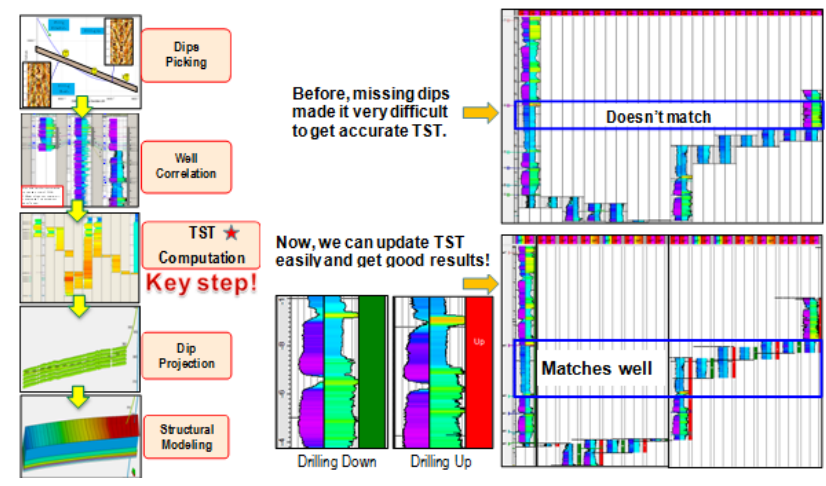

Figure 2. Structure model with eXpand ${ }^{\mathrm{BG}}$

When we do the true strategraphic thickness (TST) computation, we can check our correlation result. The TST of the bottom line is zero, and the layers should appear at more or less the same level on the TST and FMI images. After we project dips from a pilot well and horizontal well dips picked from FMI, we get the structural modelling. It shows the structure, the relationship of the well, and the formation in 3D.

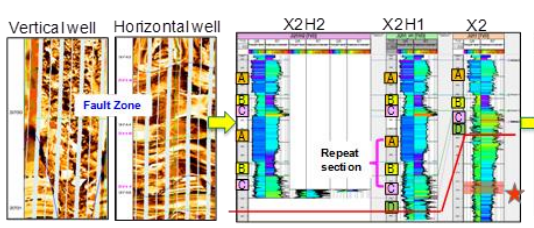
$\mathrm{X} 2 \mathrm{H} 2 \mathrm{TST}$ computation
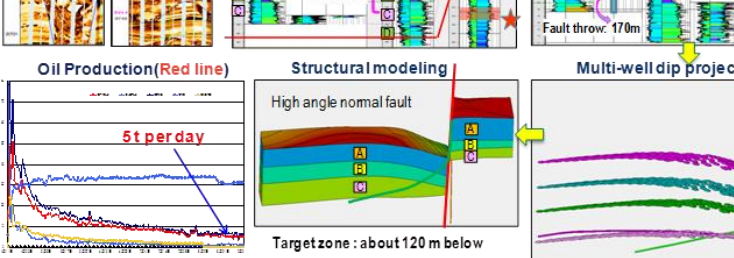

Multi-well dip projection

Figure 3. Case study using eXpandBG to analyze one failed well

Fig .3 shows another case illustrating the importance of the well correlation and structure analysis. Two sweet spots are identified in the pilot well. Obviously, the lower sweet spot is much better than the upper sweet spot. So the operator decided to drill a horizontal well targeting the lower sweet spot. However, although they drilled $400 \mathrm{~m}$ of the horizontal section, they didn't find the lower sweet spot. They thought they had already passed it, so they decided to discard the first horizontal section and drilled another 
horizontal section of $1000 \mathrm{~m}$ above the first section. Unluckily, the same thing happened: they didn't find the lower sweet spot.

By using eXpand ${ }^{\mathrm{BG}}$, we analyzed why they failed to target the lower sweet spot zone. After we checked the FMI images, we found fault zones in both the vertical and the horizontal well. Then we did a well correlation and found a repeated interval in the horizontal well, which proved that there was a fault just between the horizontal section and the vertical well. Then we did TST computation and found that the fault throw is about $170 \mathrm{~m}$. After that, we did multi-well dip projection and structural modeling. The results show a high-angle normal fault located between the vertical well and the horizontal well, and the target reservoir is still about $120 \mathrm{~m}$ below it.

Fig .4 shows another successful case where we helped the operator to target the reservoir. Based on the vertical well, the operator decided to drill horizontal wells in the upper sweet spot (No.8 to No.11, $28 \mathrm{~m}$ ). First, they drilled the sidetracking well and asked us to do the analysis and give them advice on next drilling direction.

Based on our study, the best reservoir (No.8) is about $7 \mathrm{~m}$ higher, so we suggested the operator drill up.They accepted our advice and finally drilled back to the sweet spot.
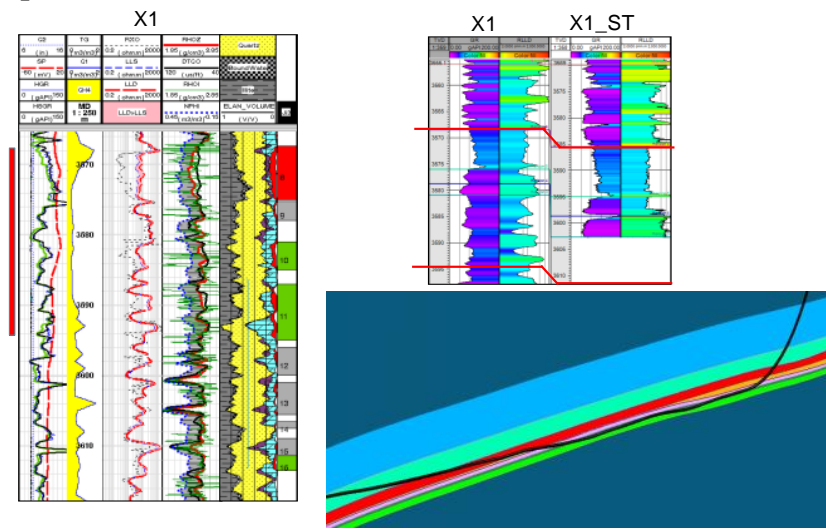

Figure 4. Case study of one succesful well using eXpand ${ }^{\mathrm{BG}}$

\section{FRACTURE EVALUATION AND ANALYSIS}

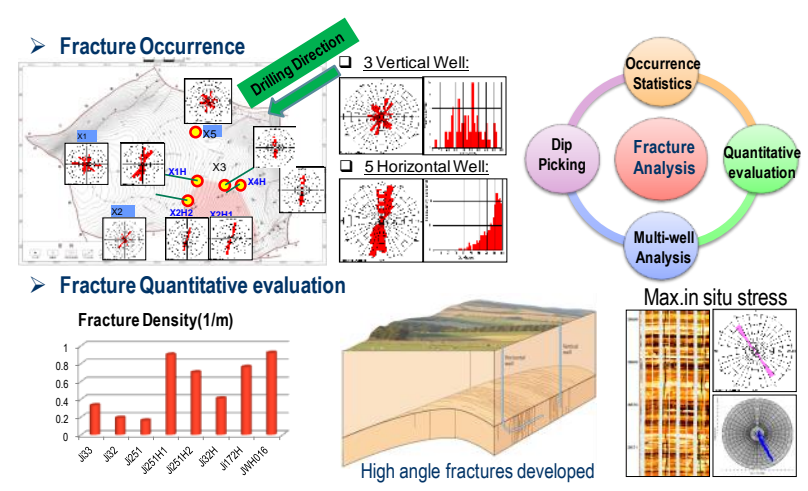

Figure 5. Fracture analysis workflow and result

With effective stimulation techniques, horizontal wells have demonstrated favorable economics compared to vertical wells in the same reservoir because they create a much larger hydraulic fracture surface area. To achieve optimum horizontal well stimulation, the lateral section must be characterized and the perforation placement customized to account for the changes in RQ and CQ along the borehole.

Fractures play an important role in RQ and CQ evaluation. Here we provided four steps for fracture evaluation, including fracture identification, occurrence statistics, quantitative evaluation, and multiwell analysis (Fig .5). After single-well interpretation; we did multiwell analysis to find the fracture characteristics in this area. We found that the fractures propagate differently between the vertical and horizontal wells: In 3 vertical wells, the fractures propogated in many directions with low angles; in 5 horizontal wells, the fractures propagated in only one direction with high angles.

Second, fracture density in horizontal wells is much higher than in vertical wells. Because this area only developed high-angle fractures, the vertical well cannot cut through many of them.

Third, by combining the natural fractures and in-situ stress direction, we suggested the drilling direction: from northeast to southwest. In this direction, the wells can cut a lot of nature fractures, the wellbore will be more stable and hydraulic fractures are more likely to stay open.

\section{Stimulation DESIGN OPTIMIZATION}

How to optimize the stimulation design has been elaborated in many papers [6-11]. Before, the stimulation design was based on the lithology and porosity along the horizontal well and information from offset wells. But now, based on previous study, we combined them with the RQ and CQ parameters from petrophysicists and geomechanical experts to provide a better solution for stimulation design (Fig .6)

First, we projected the RQ and CQ properties to the wellbore, and we could easily tell how the RQ and CQ vary.

Then we combined the RQ and CQ with the 3D property model, which showed how the reservoir develops away from the wellbore.

All this information was taken into account by the stimulation engineer to optimize the stimulation design.

This workflow has been applied to all the horizontal wells of the study area. The productivity performance is better than before.

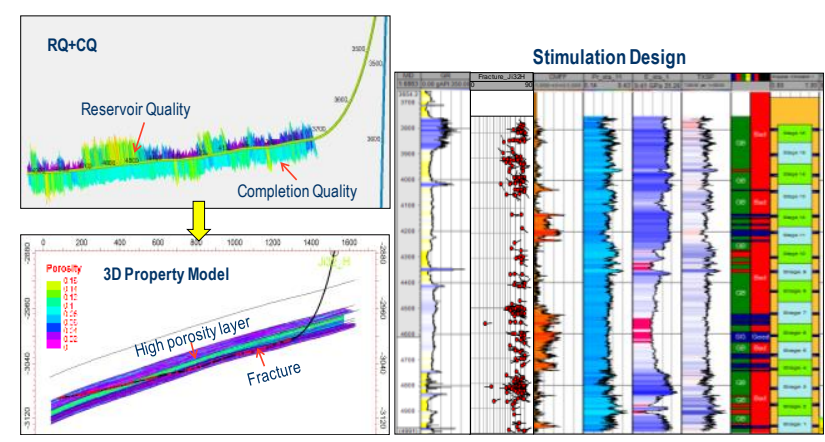

Figure 6. Workflow for stimulation design optimization 


\section{CONCLUSIONS}

Base on the integrated study of the tight oil reservoir in Jimusaer Depression, the following statements are concluded.

Reservoir Quality and Completion Quality do vary significantly along horizontal tight oil wells in the Jimusaer depression. The effects of changes in these properties may demonstrate themselves in the form of changes in production.

By combining these with the 3D property model, not only can we tell the RQ and CQ variations along the wellbore, but we also can tell how the properties develop away from the wellbore. All this information can be taken into account by the stimulation engineer to optimize the stimulation design.

Additional measurements along the lateral facilitate the assessment and understanding of individual well performance. At the same time, they provide a foundation for operators to compare production results between nearby wells on the same basis. While evaluating horizontal well completion and stimulation design changes, differences due to well positioning in relation to the geological target, reservoir property changes, hydrocarbon saturation disparity, and geomechanical property variations can be incorporated. This information accelerates the learning curve and saves on completion costs while attaining more efficient and consistent results.

\section{ACKNOWLEDGMENT}

This work was financially sponsored by the Exploration Department of Xinjiang Oilfield, CNPC. We would like to thank Xinjiang Oilfield Company, CNPC for their generosity in releasing this data, and also thanks to Dr. Xianran Zhao for his valuable ideas on unconventional formation evaluation.

\section{REFERENCES}

[1] L.C. Kuang, W.X. Hu, X.L. Wang, "Research of the tight oil reservoir in the Lucaogou formation in Jimusar sag: analysis of lithology and porosity characteristics," Geological Journal of China Universities, vol. 19, Sep. 2013, pp. 529-535

[2] L. C. Kuang, Z. C. Sun, O. Y. Min, "Complication lithology logging identification of the Lucaogou tight oil reservoir in Jimusaer depression," Well Logging Technology, vol. 37, Dec. 2013, pp. 638-642

[3] S.Y. Han, J.C.L. Kok, "Shale gas reservoir characterization using LWD in real time," Canadian Unconventional Resources \& International Petroleum Conference, Oct, 2010, doi:10.2118/ 137607-MS

[4] S.Khalid,K. Faurschou, "Mapping key reservoir properites along horizontal shale gas wells," Canadian Unconventional Resources\& International Petroleum Conference, Oct, 2010, doi:10.2118/ 137413-MS

[5] G. Waters, J. Heinze, J., "Use of horizontal well image tools to optimize Barnett shale reservoir exploitation," SPE Annual Technical Conference and Exhibition, Sep, 2006, doi: 10.2118/ 103202-MS

[6] C.L. Cipolla, E.P. Lolon, "Fracture design considerations in horizontal wells drilled in unconventional gas reservoirs," SPE Hydraulic Fracturing Technology Conference (2009)

[7] J. Daniels, G.Waters, "Contacting more of the Barnett shale through an integration of real-time microseismic monitoring," SPE Annual Technical Conference and Exhibition, Nov, 2007, doi: 10.2118/ 110562-MS

[8] A.A. Ketter, J.L. Daniels, J.R. Heinze and G. Waters, "A field study optimizing completion strategies for fracture initiation in Barnett shale horizontal wells," SPE Annual Technical Conference and Exhibition, Sep,2006,doi:10.2118/103232-MS

[9] D.I. Potapenko, S.K. Tinkham, "Barnett Sshale refracture stimulations using a Novel diversion technique," SPE Hydraulic Fracturing Technology Conference, Jan , 2009, doi: 10.2118/ 119636-MS

[10] C. Miller, G. Waters, E. Rylander, "Evaluation of production log data from horizontal wells drilled in organic shales," SPE North American Unconventional Gas Conference and Exhibition, Jun. 2011, doi:10.2118/144326-MS

[11] A.A. Ketter, J.L.Daniels, "A field study optimizing completion strategies for fracture initiation in Barnett shale horizontal wells," SPE Annual Technical Conference and Exhibition Sep,2006,doi:10.2118/103232-MS 